This item was submitted to Loughborough's Research Repository by the author.

Items in Figshare are protected by copyright, with all rights reserved, unless otherwise indicated.

\title{
Superheated water: the ultimate green solvent for separation science
}

PLEASE CITE THE PUBLISHED VERSION

PUBLISHER

(C) Springer-Verlag

LICENCE

CC BY-NC-ND 4.0

\section{REPOSITORY RECORD}

Smith, Roger M.. 2019. "Superheated Water: The Ultimate Green Solvent for Separation Science". figshare. https://hdl.handle.net/2134/2272. 
This item was submitted to Loughborough's Institutional Repository by the author and is made available under the following Creative Commons Licence conditions.

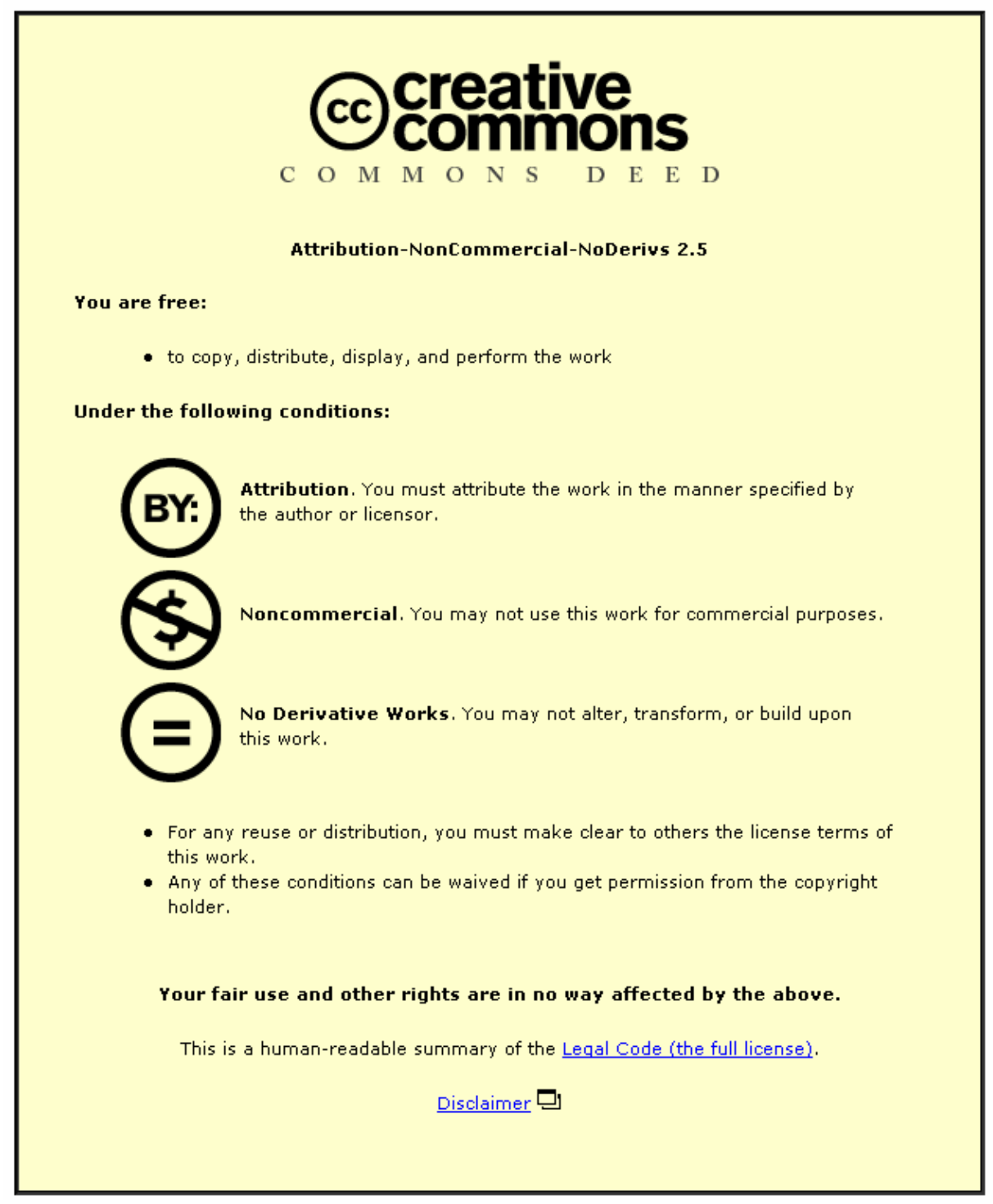

For the full text of this licence, please go to: http://creativecommons.org/licenses/by-nc-nd/2.5/ 


\title{
LLoughborough University
}

TRENDS Published in Analytical and Bioanalytical Chemistry, 385 (3) [2006]

Keywords: superheated water, extraction, chromatography, green solvent

\author{
Roger M. Smith
}

Superheated water: the ultimate green solvent for separation science

\author{
Roger M. Smith - \\ Department of Chemistry \\ Loughborough University \\ Loughborough, Leics \\ LE11 3TU, UK \\ e-mail: R.M.Smith@lboro.ac.uk
}

\section{Introduction}

Normally, chromatographers regard water in reversed-phase chromatography as a largely inert diluent, which acts to weaken the "active organic modifier", and as a "poor" solvent for most organic compounds, unless aided by ionisation. We rarely comment on its effect in separation science or consider if it has changeable properties that we can exploit. With a few exceptions, most liquid chromatography is carried out between 30 and $50^{\circ} \mathrm{C}$, however, elevated temperature has a profound effect, both on the properties and separation power of water, that we are only just starting to exploit.

When cool, water is highly polar, a weak eluent and a poor solvent for most organic analytes, but raising the temperature significantly above ambient has a dramatic effect. The hydrogen-bonding weakens and the polarity, measured as the relative permittivity, and the viscosity both decrease markedly. At $200{ }^{\circ} \mathrm{C}$, water has similar properties to an organic solvent, such as 
methanol. Water, between $100{ }^{\circ} \mathrm{C}$ and its supercritical point at $374{ }^{\circ} \mathrm{C}$, is described as by different researchers as superheated water, subcritical water or pressurised hot water and it is this region that is of interest. Only modest pressures are required to maintain the water in a condensed state and prevent steam formation, for example at $200{ }^{\circ} \mathrm{C}$ the vapour pressure of water is less than 20 bar.

By selecting appropriate temperatures, we can therefore generate a non-organic solvent with a range of properties, corresponding effectively to different compositions of methanol and water, that can be used in separations and extractions. Water has many advantages in this role, it is natural, and hence readily and widely available, usually in a high state of purity. It is non-toxic and its disposal is regarded as benign with little effect on the environment. In many ways it is the ideal low cost "green" solvent, yet it has attracted less attention than many of the so-called "ionic green solvents”, whose synthesis and disposal are currently the subject of debate. Generally, there has been a reluctance to experiment with high temperatures in HPLC, either through a concern that the mobile phase will boil, or for the stability of the column and analytes but in gas chromatography temperatures up to $400{ }^{\circ} \mathrm{C}$ are routinely employed without problems.

In the last 10 years superheated water has started to be exploited in many laboratories for both extraction and chromatography and this is a trend which should be explored further as a way of reducing costs and increasing the versatility of our analytical methodologies.

\section{Superheated water as a solvent for extraction}

In the mid 1990s Hawthorne proposed the use of superheated water as suitable solvent for the extraction of non-polar neutral compounds, such as PAHs, from environmental samples [1]. He demonstrated a dramatic $10^{5}$ fold increase in the solubility of chrysene between room temperature and water at $225^{\circ} \mathrm{C}$ [2]. He has subsequently extended these studies, including the use of water in field extraction and trapping methods.

Since then numerous other groups [3,4] have examined the use of elevated temperature water for the extraction of a wide range of analytes from different matrices, including plant materials, such as rosemary and Chinese herbal medicines. The extraction leaves no chemical residues and also can be used in soil remediation technique to leave to provide an immediately viable soil [5]. 
However, superheated water extraction has the disadvantage that the product is a cold dilute aqueous solution of the extractant. A subsequent step is often then needed to separate and concentrate the analytes, either by using solvent extraction, solid phase extraction or microextraction. Thermal desorption from the trap can be carried out to sequentially release analytes with decreasing polarity (Figure 1)[6]. Alternatively, the extraction step can be directly coupled with GC [7] or HPLC [8] so that the concentration takes place in during the injection stage. We have combined these methods for the extraction of triazines from soils, by linking superheated water extraction, followed by concentration on a cartridge and stepwise transfer to a superheated water chromatographic separation. The whole method was totally organic solvent-free and the trapping, clean-up and release of the sample to the chromatographic step was controlled purely by temperature changes [9].

Figure 1

\section{Superheated water in chromatography}

The same concepts of water as a variable solvent can be carried through to HPLC mobile phases in reversed-phase chromatography. Here there is an addition advantage that increasing the temperature effectively generates a gradient elution as the polarity of the eluent decreases. We reported that this approach was practical $[10,11]$ and together with others have demonstrated its application for a wide range of analytes, including drugs, natural products, vitamins etc [12,13]. More recently we have found that the idea had originally been reported by Guillemin and coworkers under the name of thermal aqueous liquid chromatography (TALC) [14]. However, his work was not followed up and was essential lost because the publication was in a new journal that was not widely abstracted at the time.

\section{Advantages (and disadvantages) of Superheated water in Chromatography}

Normally in HPLC we are so used to working with organic solvents that we can forget that many of the methods in current use are deliberately devised to overcome their limitations. We are restricted in the detectors that can be employed, because we are trying to differentiate between the signals of the organic analyte and the organic component of the mobile phase and we are usually restricted in the choice of mobile phase organic components by cost and safety. 
So how does superheated water overcome these problems?

Firstly, it is a green solvent - minimal cost, safe, non-toxic, non-inflammable and recyclable. The hardware required is simple, a single standard HPLC pump even for gradient elution, a GC type oven with temperature programming, a pressure resistant detector flow cell (although many standard cells will withstand the pressures required) and a method of creating a back pressure to prevent boiling, which can be as simple as a length of narrow bore tubing PEEK tubing.

Secondly, it is highly flexible, just by changing temperature, which is an accurately transferable variable - across laboratories and across continents. The reduction in viscosity with temperature enables high flow rates to be employed but gains in efficiency are limited probably because of increase band spreading due to the higher diffusion rate at elevated temperatures. We can also add buffers and control pH [15]

Thirdly, water can be used with a wide range of detectors. For example as well as being compatible with ultraviolet spectroscopy and fluorescence detection, where water has virtually no background absorbance down to $190 \mathrm{~nm}$, it can also be used with refractive index and electrochemical detection. There is no reason why it should not be compatible with evaporative light scattering detection and it has been coupled to mass spectroscopy [16].

Of greater interest is that water is also compatible with the flame ionisation detection as unlike conventional HPLC mobile phases there is no organic modifier to give a background signal[11, 17, 18 ]. It can therefore be used for the detection of analytes lacking chromophores, such as aliphatic alcohols, amino-acids and carbohydrates, as the first true universal detector in HPLC (Figure 2). Interfacing is a problem but can be overcome.

Figure 2

The absence of organic hydrogens in the eluent also means that if deuterium oxide is used as the eluent, on-line proton nuclear magnetic resonance spectroscopy (LC-NMR) give a background free signal [19]. This is much cheaper than using deuterated methanol or acetonitrile in the eluent.

\section{What more is needed?}


The widespread adoption of superheated water in chromatography still faces a number of barriers. Firstly, there is an understandably inherent conservatism in the chromatography community towards new methods until they are demonstrably better than existing techniques. These centre around worries about the stability of stationary phases and analytes. In our studies very few samples have shown instability and these have usually been compounds, such as aspirin, which are unstable even at room temperature. At the typical temperatures being employed, we have seen no evidence of hydrolysis or oxidation, even from compounds, such as the parabens (p-hydroxyl benzoate esters), which could undergo either reaction [11].

Initially the use of superheated water was hampered by a lack of stable stationary phases, most ODS-silica based columns being degraded above $80-90{ }^{\circ} \mathrm{C}$. However, alternative materials were available, such as polystyrene-divinyl benzene polymers (PS-DVB) which are stable over 200 ${ }^{\circ} \mathrm{C}$ and have been widely used. Other materials including porous graphitic carbon (Hypercarb) are also stable to high temperatures and zirconia based PBD and Diamondbond columns have worked well over $100{ }^{\circ} \mathrm{C}$. Newer hybrid materials, such as bonded Xterra and XBridge are also showing good stability and a number of similar new generation materials are being marketed.

\section{References}

$1 \quad$ Hawthorne SB, Yang Y, Miller DJ (1994) Anal Chem 66: 2912 - 2920

2 Miller DJ, Hawthorne SB, Gizir AM, Clifford AA (1998) J Chem Eng Data 43: 1043-1047

3 Smith RM (2002) J Chromatogr A 975: 31 - 46.

4 Morales-Munoz S, Luque-Garcia JL, de Castro MDL (2006) Anal Chim Acta 557: 278-286.

5 Lagadec AJM, Miller DJ, Lilke AV, Hawthorne SB (2000) Environ Sci Technol 34: 1542 1548.

6 Tajuddin R, Smith RM, (2002) Analyst 127: 883-885.

7 Hyotylainen T, Andersson T, Hartonen K. Kuosmanen K, Riekkola ML ( 2000) Anal Chem 72: 3070 - 3076.

8 Crescenzi C, Di Corcia A, Nazzari M, Samperi R (2000) Anal Chem 72: 3050-3055

9 Tajuddin R, Smith RM, (2005) J Chromatogr A 1084: 194 - 200.

10 Smith RM, Burgess RJ (1997) J Chromatogr A 785: 49 - 55.

11 Smith RM, Burgess RJ, Chienthavorn O, Stuttard JR (1999) LC GC Internat 12: 30 - 36

12 Coym JW, Dorsey JG (2004) Anal Lett 37:1013 - 1024

13 Yhu C, Goodall DM, Wren SAC (2004) LC- GC Europe 17: 530 - 540

14 Guillemin CL, Millet JL, Dubois J (1981) J High Resolut Chromatogr 4: 280-286.

15 Chienthavorn O, Smith RM (1999) Chromatographia 50: 485 - 489.

16 Smith RM, Chienthavorn O, Wilson ID, Wright B, Taylor SD (1999) Anal Chem 71: 4493 4497. 
17 Ingelse BA, Janssen HG, Cramers CA (1998) J High Resol Chromatogr 21: 613-616

18 Miller DJ, Hawthorne SB (1997) Anal Chem 69: 623 - 627.

19 Smith RM, Chienthavorn O, Wilson ID, Wright B, Taylor SD (1999) Ana Chem 71: 4493 4497. 
Figure 1 Sequential thermal release of trapped pharmaceuticals at increasing temperature and their chromatography using superheated water chromatography. Trap PS-DVB.

Column: PS-DVB column at $75-185^{\circ} \mathrm{C}$ at $15^{\circ} \mathrm{C} / \mathrm{min}$. Analytes: 1, paracetamol; 2, salicylamide; 3, caffeine; 4, methyl paraben; 5, phenacetin; 6, ethyl paraben.

Chromatograms: a, fraction untrapped at ambient temperature; b, fraction released from trap at $70{ }^{\circ} \mathrm{C}$; c, released at $90{ }^{\circ} \mathrm{C}$; d, released at $110^{\circ} \mathrm{C}$

Figure 2 Separation of a mixture of aliphatic and aromatic alcohols on PS-DVB Column at $140-180^{\circ} \mathrm{C}$ at $7^{\circ} \mathrm{min}^{-1}$ with UV and FID detection.

Error! Objects cannot be created from editing field codes. 


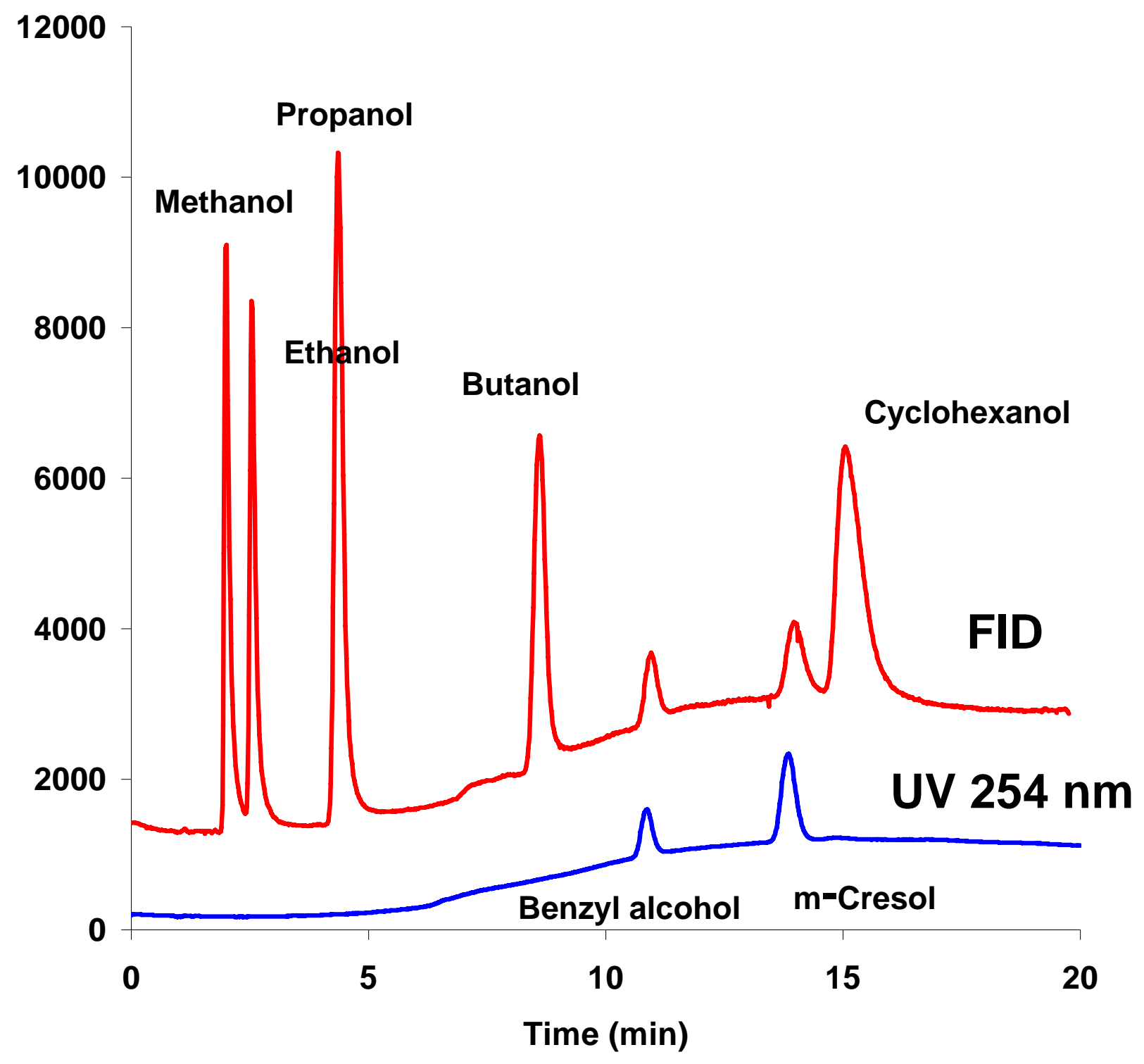

